\title{
The Genetic Structure of Populations of the Douglas-Fir Swiss Needle Cast Fungus Nothophaeocryptopus gaeumannii in New Zealand
}

\author{
P. I. Bennett,,$^{1, \dagger}$ I. A. Hood, ${ }^{2}$ and J. K. Stone ${ }^{1}$
}

${ }^{1}$ Department of Botany and Plant Pathology, Oregon State University, Corvallis 97331; and ${ }^{2}$ Scion Forest Protection, Private Bag 3020, Rotorua 3046, NZ.

Accepted for publication 16 August 2018.

\begin{abstract}
Swiss needle cast is a foliar disease of Douglas-fir (Pseudotsuga menziesii) that results in premature foliage loss and reduced growth. The causal fungus, Nothophaeocryptopus gaeumannii, was first detected in New Zealand in 1959 and spread throughout the North and South Islands over the following decades. The contemporary genetic structure of the $N$. gaeumannii population in New Zealand was assessed by analyzing 468 multilocus SSR genotypes (MLGs) from 2,085 N. gaeumannii isolates collected from 32 sites in the North and South Islands. Overall diversity was lower than that reported from native $N$. gaeumannii populations in the northwestern United States, which was expected given that $N$. gaeumannii is introduced in New Zealand. Linkage disequilibrium was significantly higher than expected under random mating, suggesting that population structure is clonal. Populations of $N$. gaeumannii in the North

and South Islands were weakly differentiated, and the isolates collected from sites within the islands were moderately differentiated. This suggests that gene flow has occurred between the N. gaeumannii populations in the North and South Islands, and between the local $N$. gaeumannii populations within each island. Eighteen isolates of $N$. gaeumannii Lineage 2, which has previously been reported only from western Oregon, were recovered from two sites in the North Island and four sites in the South Island. The most likely explanation for the contemporary distribution of $N$. gaeumannii in New Zealand is that it was introduced on infected live seedlings through the forestry or ornamental nursery trade, as the fungus is neither seed borne nor saprobic, and the observed population structure is not consistent with a stochastic intercontinental dispersal event.
\end{abstract}

The foliar disease Swiss needle cast (SNC) is specific to Douglasfir (Pseudotsuga menziesii (Mirb.) Franco), and results from cumulative occlusion of needle stomata by the ascocarps of Nothophaeocryptopus gaeumannii (T. Rohde) Videira, C. Nakash., U. Braun \& Crous (Manter et al. 2000; Stone et al. 2008a). The disease was first described from a Douglas-fir plantation in Switzerland in 1925 and became established throughout central Europe and the U.K. in the following decades (Boyce 1940; Liese 1939; Peace 1962; Rohde 1936; Wilson and Waldie 1928). However, there is ample evidence to suggest that the fungus is endemic in the native range of its host in western North America (Boyce 1940; Hood 1982; Meinecke 1939). The pathogen has since accompanied its host worldwide as exotic Douglas-fir plantings have been established for timber production. The presence of this fungus has been confirmed in Douglas-fir plantations in the northeastern United States (McCormick 1939; Morton and Patton 1970), Australia (Marks 1975), New Zealand (Hood et al. 1990; Hood and Kershaw 1975), Turkey (Temel et al. 2003), Chile (Osorio 2007), and Spain (Castaño et al. 2014). A severe outbreak of SNC that started in mid-1980s continues to intensify in the low-elevation forests along western slopes of the Coast Ranges in Oregon and Washington where both host and pathogen are native (Hansen et al. 2000; Ritóková et al. 2016; Stone et al. 2008b).

${ }^{\dagger}$ Corresponding author: Patrick Bennett; E-mail: bennetpa@oregonstate.edu

Funding: Major funding, laboratory, technical, and logistic support provided by Scion Research, Ltd. is gratefully acknowledged. Additional funding was provided from the New Zealand Ministry of Business, Innovation and Employment Strategic Science Investment Fund.

*The $\boldsymbol{e}$-Xtra logo stands for "electronic extra" and indicates that three supplementary figures are published online.

(c) 2019 The American Phytopathological Society
Douglas-fir has been cultivated as a commercial timber species in New Zealand since the early 20th century, but accounts for only a small fraction of the total forest land area and timber production (Ministry for Primary Industries 2016). The origins of Douglas-fir seed imported into New Zealand before 1926 are unknown, but plantations were established thereafter from seed sources in the Coast Ranges of Oregon, Washington, and British Columbia, with the majority of seed stock coming from southern Washington (Weston 1957). The first reported presence of $N$. gaeumannii in New Zealand was in 1959 in the North Island near Taupo, where it was initially restricted to an area with a radius of approximately $130 \mathrm{~km}$ (Hood and Kershaw 1975). However, symptoms of SNC, such as chlorosis and needle loss, were not reported in the region until 1962 (Hood and Kershaw 1975). Over the following 10 years, the fungus was found in most of the Douglas-fir plantations in the North Island and was detected for the first time in the South Island in 1969 (Hood and Kershaw 1975). By 1974, the fungus had been found throughout the Douglas-fir growing region in the northern part of the South Island, and sporadically at sites farther south (Hood and Kershaw 1975). It has been suggested that the spread of the disease to the South Island may have been due to the movement of infected seedlings from the North Island (Hood and Kershaw 1973). In total, it took approximately 30 years for $N$. gaeumannii to become established in all but a few of the most remote Douglas-fir plantations in New Zealand (Hood et al. 1990).

A comparison of the genetic structures of $N$. gaeumannii populations in New Zealand, Europe, and the United States revealed that the populations in western Oregon, where SNC symptoms had become increasingly more severe in many natural Douglas-fir stands and timber plantations, consisted of two reproductively isolated lineages (Winton et al. 2006). Lineage 1 was found to be widespread, occurring throughout the native range of Douglas-fir (except for the extreme southern coast of Oregon) 
and wherever its host was grown abroad as an exotic, including Europe and New Zealand (Winton et al. 2006). Lineage 2 was found to be much less common, occurring in pure (i.e., nonadmixed) populations along the southern Oregon coast, and in admixed populations with lineage 1 in the central and northwestern Oregon Coast Range (Bennett and Stone 2016; Winton et al. 2006). Lineage 2 was not detected in collections from Washington, the eastern United States, Europe, or New Zealand (Winton et al. 2006). At the time of this discovery, it was suggested that Lineage 2 may be responsible for the recent emergence of SNC in western Oregon, as it was found in high abundance in severely diseased stands near the coast and was often not detected in healthier stands further east (Winton et al. 2006).

The aims of this study were to (i) examine the effects of the introduction and spread of N. gaeumannii in New Zealand on the genetic structure of its populations, and (ii) determine whether $N$. gaeumannii Lineage 2 is present in New Zealand. There is evidence to suggest that this fungus is capable of homothallic reproduction, i.e., fertile asci arise from self-fertilization (asexual conidial reproduction is not known in $N$. gaeumannii) (Bennett and Stone 2016; Winton et al. 2006). Thus, we hypothesized that the introduction of $N$. gaeumannii to New Zealand would have resulted in a founder event, and successive generations of self-fertilization along with genetic drift would result in a genetic bottleneck. We also considered several hypotheses about the expected spatial genetic structure of the $N$. gaeumannii population in New Zealand, and considered two possible scenarios that might explain the current extent of colonization: (i) N. gaeumannii spread from an initial site of introduction in the North Island to its current distribution by the anthropogenic movement of infected Douglas-fir seedlings (or foliage) or long-distance aerial spore dispersal, or (ii) $N$. gaeumannii spread from the site of initial introduction via local ascospore dispersal and colonized the South Island gradually as described in Hood and Kershaw (1973). The first scenario would likely result in a relatively homogeneous distribution of $N$. gaeumannii genotypes and an abundance of shared multilocus genotypes (MLGs) between islands and sites. We might also expect the first scenario to result in a lack of isolation by distance, where genetic dissimilarity between sites is not related to geographic distance between sites. On the other hand, the second scenario should result in a more heterogeneous spatial distribution of MLGs and an abundance of regionally specific genotypes resulting from selection or genetic drift. The second scenario would be expected to result in isolation by distance.

\section{MATERIALS AND METHODS}

Field sampling, isolations, and culturing. The isolates included in these analyses were collected from Douglas-fir plantations in New Zealand in 2005 and 2007 (Stone et al. 2007; Watt et al. 2010). Foliage was sampled from 13 sites in the North Island and 19 in the South Island (Fig. 1). Samples were collected from secondary branches in the upper crowns of 10 Douglas-fir trees of the coastal variety (P. menziesii var. menziesii) at each site. Twenty needles were selected from each tree for single-ascospore isolations. Double-sided adhesive tape was used to affix 2-year-old needles bearing pseudothecia to the lids of Petri dishes. These plates were then incubated at room temperature for approximately 24 to 48 $\mathrm{h}$, during which time the ascospores discharged onto the agar surface below. Between 20 and 50 individual ascospores were isolated from each foliage sample, transferred onto $2 \%$ malt agar, and incubated for a minimum of 2 to 6 months to allow adequate growth for DNA extraction.

Molecular techniques. DNA was extracted with the procedure described in Winton et al. (2006). Briefly, mycelium was scraped from the agar surface and macerated by shaking in a minibeadbeater with glass beads and CTAB (cetyltrimethylammonium bromide) extraction buffer (Winton et al. 2006). The samples were then incubated at $65^{\circ} \mathrm{C}$ for $2 \mathrm{~h}$ and precipitated in $24: 1$ chloroform/ isoamyl alcohol (Winton et al. 2006). A QIAAmp Spin Column (Qiagen, Hilden, Germany) was then used to purify the DNA and reduce PCR inhibitors (Winton et al. 2006). Ten microsatellite loci were amplified in three multiplexed PCR reactions with fluorescently-labeled reverse primers (Bennett and Stone 2016; Winton et al. 2007). Genotyping was performed via capillary electrophoresis at the Oregon State University Center for Genome Research and Biocomputing (CGRB) with the parameters described in Winton et al. (2007) and Bennett and Stone (2016). Allele scoring was performed as described in Bennett and Stone (2016). A positive control isolate was included to ensure consistency between each independent PCR amplification and genotyping run. One of the loci, Pgdi5, did not amplify consistently for all isolates and was omitted from subsequent analyses.

Data analysis. The map of sampling sites in New Zealand was created in $\mathrm{R}$ version 3.4.1 (R Core Team 2017) with the $\mathrm{R}$ packages ggplot2 (Wickham 2016), ggrepel (Slowikowski 2017), and ggsn (Baquero 2017). The multilocus SSR genotypes for the N. gaeumannii isolates collected in New Zealand were formatted with GenAlEx 6.503 (Peakall and Smouse 2012, 2006), and imported into $\mathrm{R}$ version 3.4.1 ( $\mathrm{R}$ Core Team 2017) for use with the $\mathrm{R}$ packages poppr version 2.5.0 (Kamvar et al. 2015a, 2014), adegenet 2.0.1 (Jombart, 2008), and ade4 1.7-8 (Dray and Dufour 2007). Analyses were performed with a population hierarchy that included levels for lineage, island, and site. Implementation and interpretation of poppr graphics, as well as source code for modifying poppr output, was adapted from http://grunwaldlab.github.io/Population_Genetics_ in_R/ (Kamvar and Grünwald et al. 2016).

Genotypic and gene diversity estimates were calculated with the R package poppr (Kamvar et al. 2015a, 2014), including ShannonWeiner diversity $(H)$ (Shannon 2001) and Nei's unbiased gene diversity $\left(H_{e}\right)$ (Nei 1978). Genotypic richness was estimated as the number of expected multilocus genotypes (eMLG) in a minimum shared sample size of 10 isolates (Kamvar and Grünwald et al. 2016). Repeated MLGs occurring across the subpopulations within each level of the population hierarchy were identified with the function mlg.crosspop from the R package poppr (Kamvar et al. 2014). Because analyses of genotypic diversity are sensitive to differences in sample size between groups (Grünwald et al. 2003), $H$ was estimated from 1,000 iterations of a bootstrap analysis with rarefaction, as implemented in poppr (Kamvar et al. 2015a, 2014). Random subsamples of the data were selected such that the number of samples in each group was equal to the sample size of the group with the smallest number of samples, with a minimum rarefaction sample size of 10 (Kamvar et al. 2015a, 2014). This allowed for the direct comparison of diversity estimates among lineages, islands, and sites. Rarefaction genotypic richness curves were constructed using the vegan package in R (Oksanen et al. 2017), and a genotype accumulation curve was produced with the $\mathrm{R}$ package poppr (Kamvar et al. 2015a, 2014).

The effect of the reproductive mode of the fungus on the genetic structure of the New Zealand population was examined by estimating linkage disequilibrium. The standardized multilocus index of association, $\bar{r}_{d}$ (Agapow and Burt 2001), was calculated with the R package poppr (Kamvar et al. 2015a, 2014). Analyses were performed with the full dataset, on a clone-censored dataset (to eliminate the influence of repeated MLGs), and on the lineage 1 isolates separately (to eliminate the influence of reproductivelyisolated subpopulations). The linkage disequilibrium estimate was not calculated for the clone-corrected Lineage 2 isolates due to inadequate sample size. The observed values of $\bar{r}_{d}$ were plotted in relation to a simulated population in linkage equilibrium. The probability of obtaining the observed value of $\bar{r}_{d}$, or more extreme, under the null hypothesis of no linkage among loci $\left(\mathrm{H}_{0}: \bar{r}_{d}=0\right)$ was calculated with 999 permutations of the data.

Genetic structure due to differentiation among subpopulations was evaluated with a hierarchical analysis of molecular variance 
(AMOVA) (Excoffier et al. 1992) in the R package poppr (Kamvar et al. 2015a, 2014), and utilized the ade4 implementation (Dray and Dufour 2007). This method partitioned the genetic variance within and among populations and subpopulations across all levels of the population hierarchy, which was clone-censored with respect to hierarchical level. Fixation indices ( $\phi$ statistics) were interpreted as measures of subpopulation differentiation (Excoffier et al. 1992). The probability of obtaining the observed $\phi$, or more extreme, under the null hypothesis of no differentiation between subpopulations $\left(\mathrm{H}_{0}: \phi=0\right)$ was obtained from 1,000 iterations of a permutation test implemented with the R package ade4 (Dray and Dufour 2007).

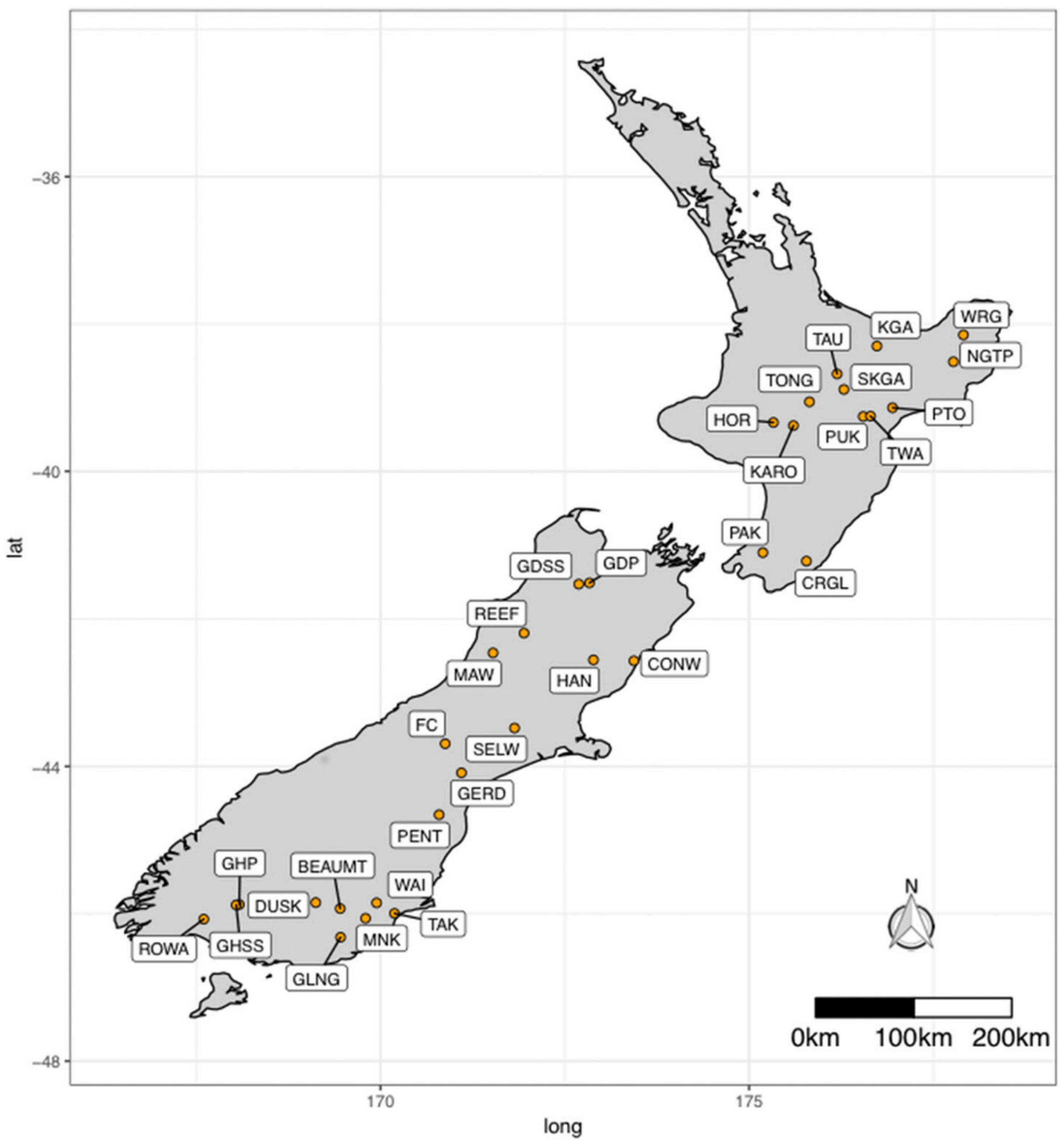

Fig. 1. Locations of 32 sampling sites from which foliage was collected for isolation of Nothophaeocryptopus gaeumannii in New Zealand. Sites were Craigie Lea (CRGL), Horopito (HOR), Karioi (KAR), Kaingaroa (KGA), Ngatapa (NGTP), Pakuratahi (PAK), Putorino (PTO), Puketitiri (PUK), South Kaingaroa (SKGA), Tauhara (TAU), Tongariro (TONG), Te Waka (TWA), and Wairangi (WRG) on the North Island and Beaumont (BEAUMT), Conway Hills (CONW), Dusky (DUSK), Forest Creek (FC), Golden Downs (Progeny) (GD-P), Golden Downs (Seed Source) (GD-SS), Geraldine (GERD), Gowan Hills (Progeny) (GH-P), Gowan Hills (Seed Source) (GH-SS), Glenelg (GLNG), Hanmer (HAN), Mawhera (MAW), Manuka Awa (MNK), Pentland Hills (PENT), Reefton (REEF), Rowallen (ROWA), Selwyn (SELW), Takitoa (TAK), and Waipori (WAI) on the South Island. 
Subpopulation differentiation between islands and sites within islands was further explored with discriminant analysis of principal components (DAPC), a multivariate analysis of genetic clustering among isolates (Jombart et al. 2010). The function xvaldapc from the R package adegenet (Jombart 2008) was utilized with a dataset that was clone-censored with respect to the hierarchical level of interest. For the DAPC analyses presented here, the number of principal components corresponding to the lowest mean squared error was selected via cross-validation, with a training set consisting of $90 \%$ of the data (Jombart and Collins 2015).

Similarities among the MLGs were visualized as a UPGMA dendrogram constructed with 10,000 replicates of a bootstrap analysis of Nei's genetic distance (Nei 1978, 1972). This analysis was performed with the aboot function in the R package poppr (Kamvar et al. 2015a, 2014), and the dendrogram was visualized with the R package ggtree version 1.12.0 (Yu et al. 2017).

Mantel's test (Mantel 1967) was performed with the R package ade4 (Dray and Dufour 2007). This test utilizes a regression approach to test for a statistical correlation between a matrix containing pairwise Euclidean geographic distances among the 32 sample sites and a matrix containing pairwise values for Roger's genetic distance (Rogers 1972) among the sites. The genetic distance among sites was calculated with the $\mathrm{R}$ package adegenet (Jombart 2008). A randomization test with 10,000 permutations was employed to test the null hypothesis of no correlation between genetic distance and geographic distance $\left(\mathrm{H}_{0}: r=0\right)$.

\section{RESULTS}

Genetic diversity. Of the 2,085 total isolates analyzed for this study, 468 unique MLGs were detected. The genotype accumulation curve showed that $90 \%$ of the MLGs could be distinguished on the basis of eight SSR loci (Supplementary Fig. S1). A total of 2,067 of the isolates were associated to lineage 1 , while 18 isolates were associated to Lineage 2 (Table 1). The Lineage 2 isolates were collected from Forest Creek (FC), Golden Downs (GD-P, GD-SS), Kaingaroa (KGA), South Kaingaroa (SKGA), and Mawhera (MAW). Even with a large sample size, we did not capture all of

TABLE 1. Sample sizes and diversity estimates for the Nothophaeocryptopus gaeumannii isolates collected from 32 sites in the North and South Islands of New Zealand

\begin{tabular}{|c|c|c|c|c|c|c|}
\hline Population level & $\mathrm{N}_{\text {isolates }}{ }^{\mathrm{a}}$ & $\mathrm{MLG}^{\mathrm{b}}$ & $\mathrm{eMLG}^{\mathrm{c}}$ & $\mathrm{SE}^{\mathrm{d}}$ & $H^{* \mathrm{e}}$ & $H_{e}^{\mathrm{f}}$ \\
\hline \multicolumn{7}{|l|}{ Lineage } \\
\hline L1 & 2,067 & 464 & 14.4 & 1.68 & 2.56 & 0.65 \\
\hline L2 & 18 & 4 & 4 & 0 & 1.24 & 0.43 \\
\hline Total lineage & 2,085 & 468 & 14.4 & 1.67 & 2.57 & 0.66 \\
\hline \multicolumn{7}{|l|}{ North Island } \\
\hline Craigie Lea (CRGL) & 47 & 25 & 7.70 & 1.21 & 1.93 & 0.55 \\
\hline Horopito (HOR) & 25 & 15 & 7.59 & 1.11 & 1.92 & 0.46 \\
\hline Karioi (KAR) & 168 & 64 & 8.51 & 1.08 & 2.08 & 0.64 \\
\hline Kaingaroa (KGA) & 176 & 56 & 7.10 & 1.36 & 1.78 & 0.48 \\
\hline Ngatapa (NGTP) & 49 & 21 & 7.36 & 1.19 & 1.89 & 0.53 \\
\hline Pakuratahi (PAK) & 46 & 21 & 7.57 & 1.16 & 1.94 & 0.41 \\
\hline Putorino (PTO) & 18 & 10 & 6.52 & 1.02 & 1.68 & 0.31 \\
\hline Puketitiri (PUK) & 60 & 33 & 8.30 & 1.13 & 2.02 & 0.52 \\
\hline South Kaingaroa (SKGA) & 46 & 27 & 8.76 & 0.94 & 2.13 & 0.60 \\
\hline Tauhara (TAU) & 177 & 112 & 9.49 & 0.70 & 2.23 & 0.65 \\
\hline Tongariro (TONG) & 24 & 15 & 7.62 & 1.10 & 1.93 & 0.44 \\
\hline Te Waka (TWA) & 64 & 31 & 7.79 & 1.21 & 1.96 & 0.37 \\
\hline Wairangi (WRG) & 53 & 35 & 8.59 & 1.07 & 2.08 & 0.54 \\
\hline Total North Island & 953 & $335 * *$ & - & - & - & 0.64 \\
\hline \multicolumn{7}{|l|}{ South Island } \\
\hline Beaumont (BEAUMT) & 154 & 48 & 8.10 & 1.14 & 2.02 & 0.53 \\
\hline Conway Hills (CONW) & 12 & 7 & 6.00 & 0.67 & 1.50 & 0.44 \\
\hline Dusky (DUSK) & 29 & 12 & 5.66 & 1.21 & 1.54 & 0.25 \\
\hline Forest Creek (FC) & 25 & 10 & 6.08 & 1.05 & 1.65 & 0.23 \\
\hline Golden Downs (Progeny) (GD-P) & 127 & 28 & 5.37 & 1.35 & 1.36 & 0.23 \\
\hline Golden Downs (Seed Source) (GD-SS) & 71 & 26 & 7.37 & 1.22 & 1.88 & 0.54 \\
\hline Geraldine (GERD) & 15 & 7 & 6.02 & 0.72 & 1.69 & 0.34 \\
\hline Gowan Hills (Progeny) (GH-P) & 170 & 49 & 7.64 & 1.23 & 1.93 & 0.68 \\
\hline Gowan Hills (Seed Source) (GH-SS) & 91 & 21 & 6.03 & 1.28 & 1.60 & 0.62 \\
\hline Glenelg (GLNG) & 22 & 10 & 6.83 & 0.96 & 1.82 & 0.39 \\
\hline Hanmer (HAN) & 138 & 39 & 7.16 & 1.31 & 1.82 & 0.59 \\
\hline Mawhera (MAW) & 10 & 2 & 2.00 & 0.00 & 0.50 & 0.20 \\
\hline Manuka Awa (MNK) & 48 & 12 & 4.99 & 1.22 & 1.30 & 0.30 \\
\hline Pentland Hills (PENT) & 12 & 9 & 7.82 & 0.65 & 1.98 & 0.31 \\
\hline Reefton (REEF) & 18 & 7 & 5.65 & 0.80 & 1.61 & 0.50 \\
\hline Rowallen (ROWA) & 38 & 14 & 6.94 & 1.09 & 1.82 & 0.48 \\
\hline Selwyn (SELW) & 12 & 11 & 9.32 & 0.47 & 2.21 & 0.41 \\
\hline Takitoa (TAK) & 17 & 11 & 7.24 & 1.01 & 1.85 & 0.47 \\
\hline Waipori (WAI) & 123 & 30 & 5.89 & 1.35 & 1.55 & 0.44 \\
\hline Total South Island & 1,132 & $193 * *$ & - & - & - & 0.64 \\
\hline Total & 2,085 & $468 * *$ & 8.73 & 1.06 & 2.12 & 0.66 \\
\hline
\end{tabular}

a $\mathrm{N}_{\text {isolates }}=$ number of $N$. gaeumannii isolates.

b $\mathrm{MLG}=$ number of multilocus genotypes.

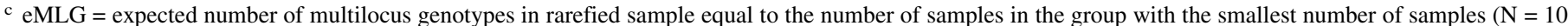
isolates for pooled sites).

d $\mathrm{SE}=$ standard error of eMLG estimate.

e $H=$ Shannon-Weiner diversity index (Shannon 2001).

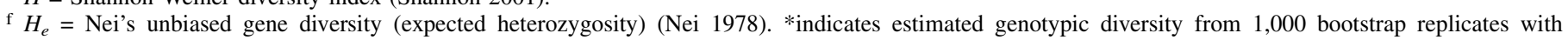
rarefaction sample sizes equal to the number of samples in the group with the smallest number of samples $(\mathrm{N}=10$ isolates for pooled sites). $-=$ data not calculated. ** indicates total MLG not equal to the sum of population totals due to shared MLGs. 
the expected genetic variation in lineage 1 (Supplementary Fig. S2). However, the four MLGs from the 18 Lineage 2 isolates were sufficient to represent the expected genetic variation within Lineage 2. Lineage 2 had lower genetic diversity than lineage 1 after accounting for differences in sample size via rarefaction (Table 1).

Overall, genotypic diversity and richness were higher for the North Island populations, but gene diversity did not differ considerably between the $N$. gaeumannii populations in the North and South islands (Table 1). Isolates sampled from Tauhara (TAU), near Taupo in the central part of the North Island, had the highest genotypic diversity of all sites in New Zealand, the highest genotypic richness, and the second highest gene diversity (Table 1). The lowest diversity was observed for the N. gaeumannii isolates collected at the South Island site Mawhera (Table 1).

Population structure and differentiation. The observed value of the multilocus index of association $\left(\bar{r}_{d}\right.$; Agapow and Burt 2001), an estimate of linkage disequilibrium, for the total New Zealand population $(N=2,085$ isolates) was significantly larger than expected for the simulated population in which there was no linkage among loci $\left(\bar{r}_{d}=0.307, P=0.001\right)$ (Supplementary Fig. S3). This indicates that alleles do not pair randomly in MLGs, and thus the population is not panmictic. This linkage disequilibrium was also detected, though to a lesser extent, when the repeated MLGs (i.e., clones) were removed from the data ( $N=468$ isolates) $\left(\bar{r}_{d}=\right.$ $0.130, P=0.001)$. Linkage disequilibrium was slightly less when the analysis was performed with only the unique lineage 1 MLGs ( $n$ $=464$ isolates) $\left(\bar{r}_{d}=0.126, P=0.001\right)$.

The partitioning of molecular variance within and among the levels of a clone-corrected population hierarchy indicated that most of the genetic variation was within sites (Table 2). Strong genetic differentiation was detected between the two $N$. gaeumannii lineages (Table 2). Moderate genetic differentiation was detected between sample sites within the islands, but there little genetic differentiation between the North and South Island populations (Table 2).

Many isolates had a high probability of being assigned to the North Island cluster, even if they had been collected in the South Island, and vice versa. The bar plot produced from the DAPC with clusters representing the North and South Islands showed a high degree of admixture, as the bars representing each genotype had high probabilities of membership in both clusters (Fig. 2A). The DAPC scatterplot depicting the relationships among isolates collected from each of the sites in New Zealand showed considerable overlap among sites, with few isolates lying outside of the central cluster of points (Fig. 2B). The isolates that appeared to be the most highly differentiated in this plot are the N. gaeumannii Lineage 2 genotypes from South Kaingaroa (North Island), Mawhera (South Island), and Golden Downs (South Island) (Fig. 2B).

The isolates corresponding to lineages 1 and 2 clustered into distinct groups in the UPGMA dendrogram based on Nei's genetic distance. These clusters were separated at the basal node with strong bootstrap support (Fig. 3).

Spatial distributions of multilocus genotypes. A total of 104 MLGs occurred at more than one site. Sixty of those 104 MLGs were recovered from both islands (Table 1, Fig. 4). The most

TABLE 2. Hierarchical analysis of molecular variance (AMOVA) performed with clone-corrected dataset including unique SSR multilocus genotypes from 468 Nothophaeocryptopus gaeumannii isolates collected from 32 sites in the North and South Islands of New Zealand

\begin{tabular}{lcrr}
\hline Hierarchical level & Variance $(\%)$ & \multicolumn{1}{c}{$\phi$} & \multicolumn{1}{c}{$P^{\mathrm{a}}$} \\
\hline$\phi_{\mathrm{LT}}$ (between lineages) & 33.546 & 0.335 & $<0.001$ \\
$\phi_{\mathrm{IL}}$ (between islands within lineages) & 0.245 & 0.004 & 0.222 \\
$\phi_{\mathrm{SI}}$ (between sites within islands) & 8.264 & 0.125 & $<0.001$ \\
$\phi_{\mathrm{SS}}$ (within sites) & 57.945 & 0.421 & $<0.001$ \\
\hline
\end{tabular}

a $P$ value was obtained for the $\phi$ statistic with 1,000 permutations of the data. common genotype (MLG 261) was shared among 291 individuals (Fig. 4), and was present at 17 sites across the North and South Islands. There were 104 unique (private) alleles in the South Island subpopulation, and 71 private alleles the North Island subpopulation. There was no isolation by distance detected, as no significant correlation was found between the geographic and genetic distance matrices $(r=-0.013, P=0.562)$. The 18 Lineage 2 isolates comprised only four distinct MLGs (Table 1, Fig. 5). One Lineage 2 MLG was collected from two sites in the North Island: Kaingaroa (KGA) and South Kaingaroa (SKGA), while the other three Lineage 2 MLGs were present at four sites in the South Island: Golden Downs (GD-SS and GD-P), Mawhera (MAW), and Forest Creek (FC) (Fig. 5). The most common Lineage 2 genotype (MLG 11) occurred at both Mawhera and Forest Creek (Fig. 5), and the second Lineage 2 genotype that occurred at Mawhera (MLG 10) was also present at a Golden Downs site (GD-P).

A

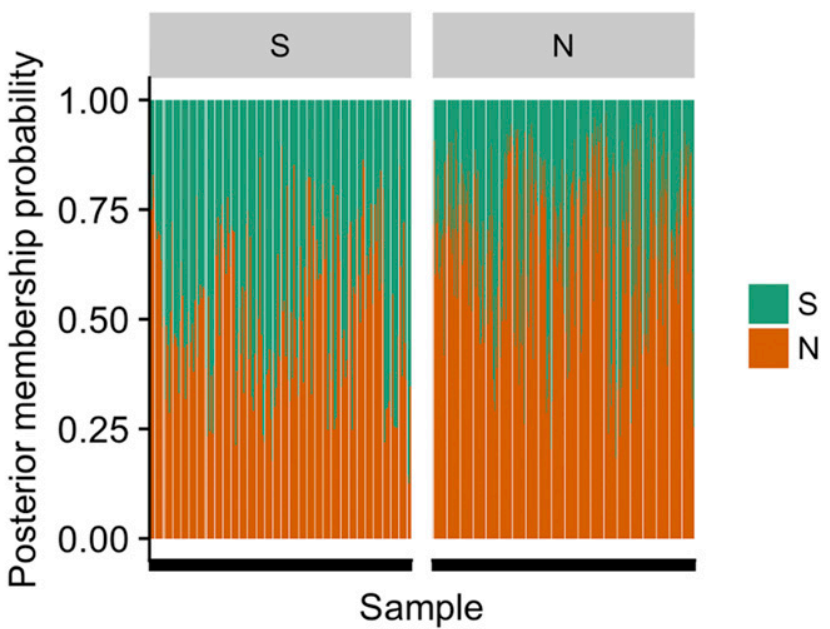

B

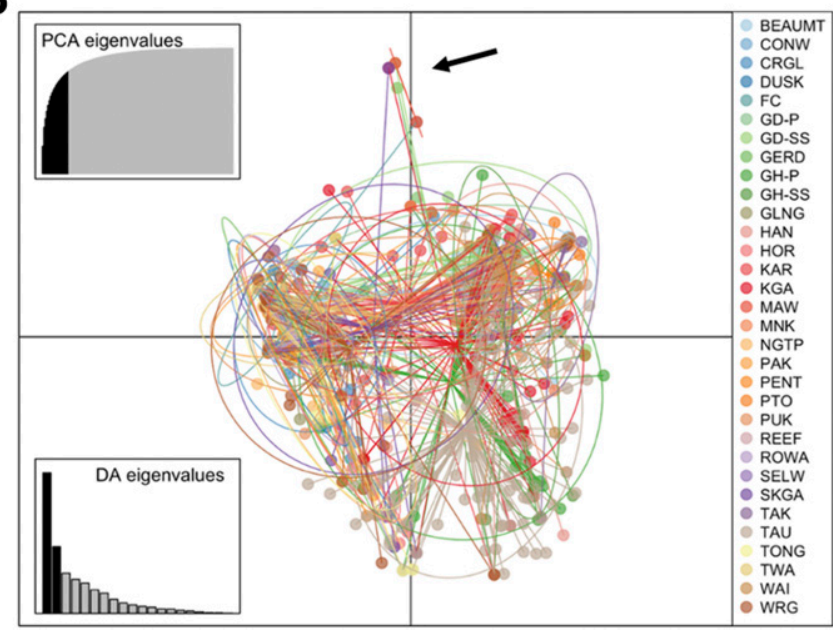

Fig. 2. A, Bar plot from discriminant analysis of principal components (DAPC) showing posterior membership probabilities of 468 Nothophaeocryptopus gaeumannii multilocus genotypes (MLGs) in clusters representing the North (N) and South (S) Islands of New Zealand. Each bar represents one MLG, and the colored portion of each bar represents the probability of membership of that MLG in the North and/or South Island clusters. B, DAPC scatterplot showing clustering among MLGs from 32 sites. Each color represents a cluster (here, a site), and each point represents an MLG. Overlapping points represent identical MLGs. Inertia ellipses are drawn around 2/3 of the isolates in each cluster. The inset at top left indicates the proportion of principal components retained, while the graph at lower left indicates the number of discriminant functions retained. The legend at right shows the site name abbreviations corresponding to each cluster (Table 1, Fig. 1). The arrow in B points to the divergent genotypes (Lineage 2) from Mawhera (MAW), South Kaingaroa (SKGA), and Golden Downs (GD). 


\section{DISCUSSION}

Populations of N. gaeumannii in New Zealand exhibit characteristics that are typical of an introduced pathogen. Estimates of both Shannon diversity and Nei's gene diversity were lower for the total New Zealand population compared with the U.S. population (4.59 versus 6.09 and 0.655 versus 0.820 for $H$ and $H_{e}$, respectively) (Bennett and Stone 2016). This, along with the high linkage disequilibrium observed, may indicate a genetic bottleneck whereby a small group of individuals was introduced in one or more discrete events, and a founder effect due to subsequent genetic drift in the introduced population. Isolates from Tauhara (TAU), a site in the central North Island near Taupo where $N$. gaeumannii was first reported in 1959, had the highest genotypic diversity and richness (Table 1). This is consistent with the central North Island being the locus of initial introduction of N. gaeumannii, as suggested by Hood and Kershaw (1975). However, isolates recovered from this site consisted of lineage 1 genotypes exclusively. Isolates of Lineage 2 were recovered nearby at Kaingaroa, but their MLGs were not similar to the Lineage 2 isolates collected from the South Island sites Mawhera, Forest Creek, and Golden Downs (Fig. 5). The presence of distinct Lineage 2 MLGs in the North and South Islands could be the result of independent introductions from western North America, as these isolates exhibited combinations of alleles in MLGs that, until now, have only been detected in western Oregon (Bennett and Stone 2016; Winton et al. 2006). This strongly suggests that the New Zealand $N$. gaeumannii population originated from a source in the coastal Douglas-fir forests of western North America.

One potential limitation of the sampling design for this study is that there was unequal sampling among the levels of the population hierarchy. Although foliage was collected from 10 trees at each site, the number of isolates collected from each of the trees was not uniform. This was due to variation in infection levels, as well as sample loss due to culture contamination. Another factor that contributed to unequal sample sizes was that not all sites were sampled in both years. Those that were sampled in only 2005 or 2007 generally had fewer isolates. We attempted to account for unequal sample sizes by using rarefaction when calculating genetic diversity and richness.

The reproductive biology of $N$. gaeumannii appears to have had a strong influence on the contemporary structure of the introduced New Zealand population. Estimates of the multilocus index of association suggested that alleles in this population do not associate randomly in multilocus genotypes, as would be expected in a random-mating population (Agapow and Burt 2001). For a haploid fungus, self-fertilization and asexual reproduction both can result in clonal population structures (Taylor et al. 1999; Winton et al. 2006). The clonal population structure we observed might be expected to result from asexual reproduction via mitospores (conidia), except that conidial reproduction has not been observed in N. gaeumannii, despite considerable scrutiny (Stone et al. 2008a). Rather, the explanation for this population structure appears to be that $N$. gaeumannii is homothallic, resulting in progeny that are genetically identical to the parent. An alternative explanation is that $N$. gaeumannii is outcrossing, but recombination between individuals with similar or identical MLGs does not lead to significant change in genetic diversity.

Significant linkage disequilibrium was also detected, albeit to a lesser degree, when repeated MLGs were removed, suggesting that the population structure of $N$. gaeumannii is strongly influenced by its reproductive mode. High linkage disequilibrium due to the presence of clones is often interpreted as evidence of an "epidemic" population structure in pathogenic microbes, whereby natural selection results in an abundance of certain genotypes that have superior fitness (often due to greater virulence or aggressiveness) relative to the rest of the population (Smith et al. 1993). In addition to the observation that a few genotypes were particularly abundant in this invasive population, the high linkage disequilibrium due to large numbers of clones could be an indication of such an epidemic population structure in New Zealand. However, the relative aggressiveness of the overrepresented genotypes has not been examined experimentally, and disease severity does not appear to coincide with the distribution of Lineage 2 or the overrepresented genotypes (discussed below). The apparent linkage disequilibrium was also due, at least in part, to the presence of reproductivelyisolated subpopulations (i.e., lineages 1 and 2). When the two lineages were analyzed separately, $\bar{r}_{d}$ for the lineage 1 subpopulation was reduced. However, after removing duplicate MLGs from the dataset, linkage disequilibrium for the lineage 1 subpopulation was still much higher than would be expected with random mating. High linkage disequilibrium in the absence of repeated MLGs and reproductively isolated subpopulations may have resulted from a bottleneck due to the introduction of a small founding population in which allele frequencies were subsequently altered by genetic drift (Hartl and Clark 2007).

The AMOVA and bootstrap analyses revealed that the lineages were strongly differentiated, as they accounted for a large proportion of the between-population variation, and were separated at a basal node into distinct clusters on the UPGMA dendrogram with strong statistical support. These results are consistent with the findings of Winton et al. (2006), who provided evidence that the two $N$. gaeumannii lineages are reproductively isolated in endemic populations in the northwestern United States. In addition to a thorough examination of morphological, biochemical, and ecological traits that might differ between the two lineages, nucleotide sequence data from multiple genes (or full genomes) should be analyzed to determine whether sufficient evidence exists to recognize them as separate species.

Given that the Douglas-fir production regions in the North and South Islands are very patchy and do not form a contiguous distribution, we expected that spread via aerial ascospore

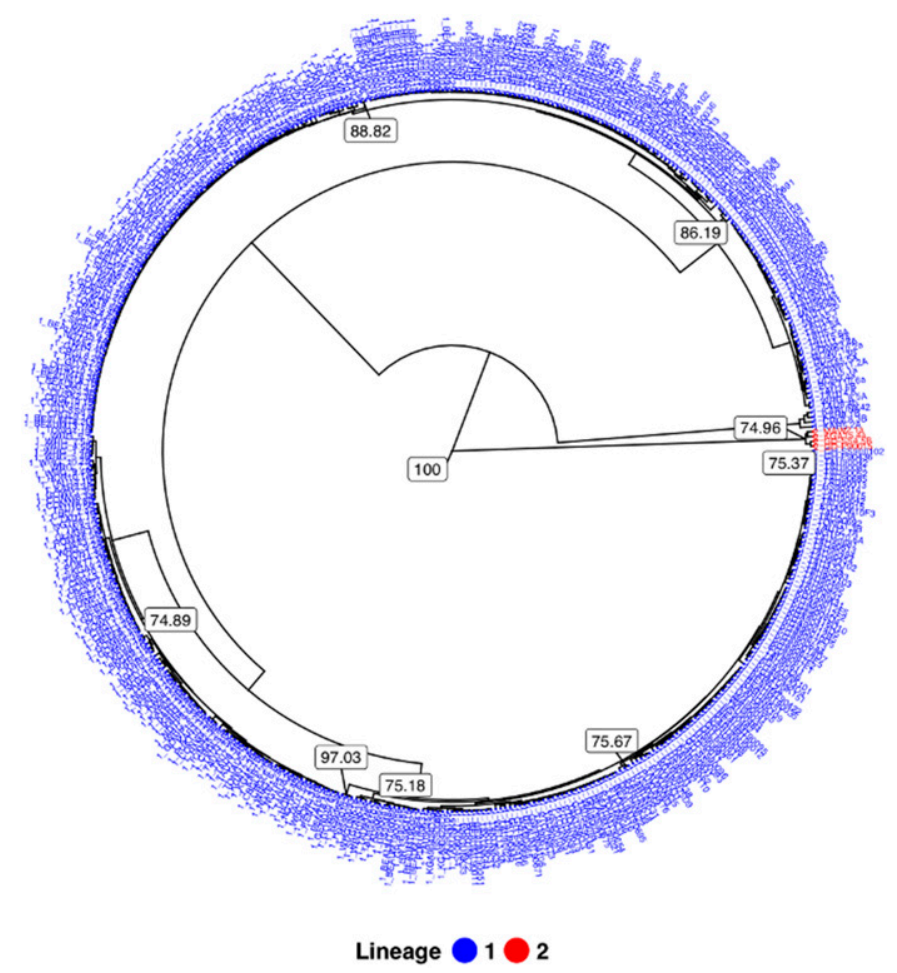

Fig. 3. UPGMA dendrogram from a bootstrap analysis of Nei's genetic distance (Nei 1972, 1978) showing divergence among Nothophaeocryptopus gaeumannii multilocus genotypes (MLGs) corresponding to two lineages from New Zealand (clone-censored, $N=468$ ). Node labels represent bootstrap statistics $(\geq 70 \%)$ from 10,000 replicate trees. 
dispersal would result in some genetic differentiation between the islands, and between sites within the islands, due to dispersal limitations. However, only a very small proportion of the overall genetic variation occurred between islands (Table 2), and there was little genetic differentiation between them (Table 2, Fig. 2A). The lack of genetic differentiation between the North and South Islands is further supported by the fact that there were 60 shared MLGs between them (Fig. 4). Despite the apparent lack of differentiation, there were private alleles that were unique in the North and South Islands. This could be due to independent introduction events or genetic divergence due to mutation, selection, or drift.

A moderate, but significant, degree of genetic differentiation was identified among the isolates collected from sites within the islands, but there was little differentiation among genotypes from the 32 sites (Fig. 2B). Several Lineage 2 genotypes fell outside of the central cluster of points in the DAPC scatter plot suggesting that some of the genetic variation among sites was due to the presence of Lineage 2 (Fig. 2B). Still, the majority of the genetic variation was partitioned to the within-site component, suggesting that gene flow has occurred between them (Table 2).

There were 104 MLGs that occurred at more than one site, and the most common MLG was shared by 271 individuals (Fig. 4) across 17 sites. This MLG was present at both Wairangi (North Island) and Gowan Hills (South Island), which are nearly 1,000 km apart (Fig. 1). However, our ability to distinguish genotypes could have been enhanced if additional loci had been included. Despite the large

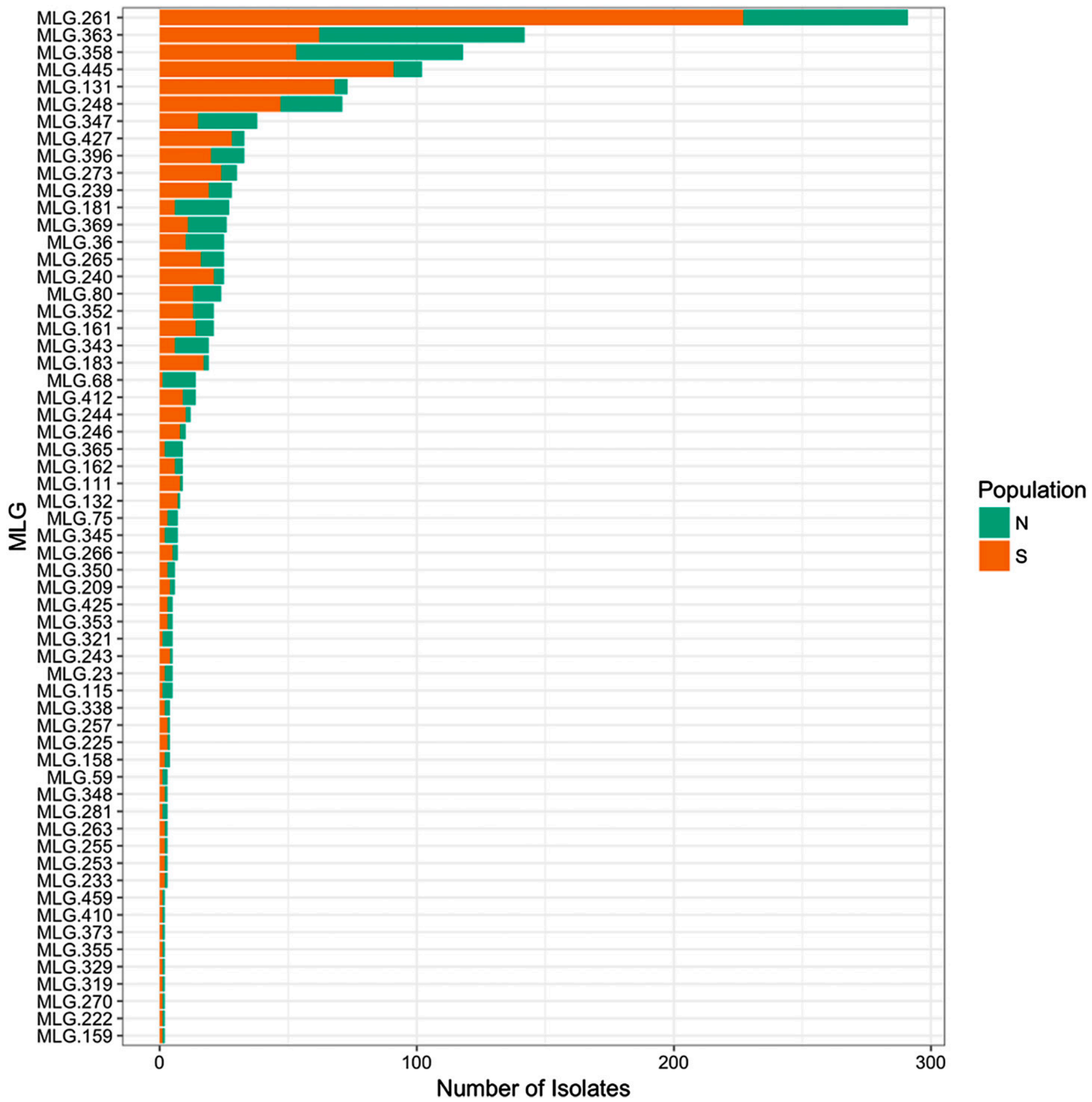

Fig. 4. Abundances of the 60 Nothophaeocryptopus gaeumannii simple sequence repeat multilocus genotypes (MLGs) shared between the North (N) and South (S) Islands of New Zealand. Each bar represents a unique MLG, with the shaded portions of each bar corresponding to the number of isolates with that MLG on each island. 
number of samples and the fact that the genotype accumulation curve suggested that we should have been able to resolve $90 \%$ of the MLGs with only eight loci, the rarefaction curve indicated that we were not able to capture all of the expected genetic variation within lineage 1 . This also suggests that had we continued to genotype more lineage 1 isolates, we would have continued to discover new genotypes.

There was no isolation by distance in the New Zealand $N$. gaeumannii populations, as no correlation between the genetic distances and geographic distances among sites was detected. The distribution of lineage 1 MLGs across New Zealand was relatively homogeneous, with few genetic barriers or dispersal limitations. Hood and Kershaw (1975) and Hood et al. (1990) documented the gradual spread of $N$. gaeumannii from a single introduction locus near Taupo to the rest of the North Island, and subsequently throughout the South Island, over a period of approximately 30 years. A gradual spread and colonization via the aerial dispersal of ascospores over short distances would be expected to result in some genetic differentiation between the islands, or between sites within each island. The effects of random dispersal, local adaptation, mutation, natural selection, and genetic drift would presumably lead to genetic variation across sites over time. Unless long-distance ascospore dispersal occurs regularly, the gradual expansion from a single source would also be expected to result in an isolation by distance phenomenon whereby genetic dissimilarity increases with the geographic distance between sites. A similar line of reasoning was used to test hypotheses about the introduction and spread of the sudden oak death pathogen, Phytophthora ramorum, in Oregon. Kamvar et al. (2015b) described the spread of $P$. ramorum populations from two points of introduction. Those authors suggested that it was the accumulation of mutations during the spread of these clonal populations that resulted in isolation by distance, and that this pattern would not be expected to occur if the spread had occurred via long distance dispersal (Kamvar et al. 2015b). Since we did not observe isolation by distance associated with the introduction and spread of N. gaeumannii in New Zealand, we can infer that either mutation rates are low, or that migration rates between sites are high. An alternative explanation for the lack of differentiation between islands, and between sites within islands, is a "stepping-stone" hypothesis in which connectivity between distant patches of a host plant may be attained by ascospore dispersal over shorter distances (Linde et al. 2002). The colonization of isolated Douglas-fir plantations via human-mediated dispersal by movement of infected plant material, or long-distance aerial ascospore dispersal among sites within and between islands could also have resulted in the observed lack of differentiation between sites. The aerial dispersal of ascospores over $1,000 \mathrm{~km}$ would be exceedingly rare (Brown and Hovmøller 2002; Rivas et al. 2004). The observed distribution of MLGs also could have resulted from the establishment of Douglas-fir plantations in the North and South Islands with infected seedlings from a single source population such as a nursery.

Given that there has apparently been gene flow between the Douglas-fir plantations in the North and South Islands, the fact that there were Lineage 2 MLGs that were relatively abundant in the South Island but were not detected in the North Island suggests that there may have been a separate introduction to the South Island from a source in western North America. However, it is possible that either the observed distribution of Lineage 2 genotypes resulted from a single introduction near Taupo and our sampling did not recover Lineage 2 MLGs that were present, or that Lineage 2 genotypes initially present in the North Island spread to the South Island but subsequently went extinct in the North Island. The latter, however, is a much less parsimonious explanation. Nevertheless, the four MLGs we detected from 18 Lineage 2 isolates seemed to account for all of the expected genotypic richness in Lineage 2. It is also possible that differentiation of local populations where Lineage 2 was abundant in the South Island, i.e., at Golden Downs and Mawhera, has occurred via natural selection, or is due to processes such as genetic drift, which is particularly influential in small populations such as these (Hartl and Clark 2007).

One major question that remains largely unanswered is whether the genetic variation in $N$. gaeumannii is related to SNC severity. Winton et al. (2006) suggested that Lineage 2 may have contributed to the emergence of SNC in the native range of Douglas-fir, as they found that a higher Lineage 2 to lineage 1 ratio was associated with lower canopy density and increased foliage discoloration in some stands in coastal northwestern Oregon. The distribution of Lineage 2 in the northwestern Coast Ranges in Oregon and Washington generally corresponds to the region where SNC is most severe (Bennett and Stone 2016; Winton et al. 2006). This suggests that there is some variation in aggressiveness between strains of this fungus (Winton et al. 2006). However, a difference in aggressiveness between the two lineages has not been definitively demonstrated. In New Zealand, the geographic distribution of Lineage 2 was very limited and was not restricted to sites with severe disease (data not shown). Much of the variation in SNC severity among sites occurred where $N$. gaeumannii Lineage 2 was absent. The fact that disease severity seemed to vary across sites in New Zealand despite the fact that the lineage 1 genotypes were relatively uniformly distributed in both the North and South Islands suggests that there is no clear association between specific genotypes or lineages and disease. The observed spatial variation in SNC severity in New Zealand is much more likely to be a function of climate, as areas with warmer winter temperatures and more precipitation in spring and early summer generally have more severe SNC symptoms (Stone et al. 2007; Watt et al. 2010).

The records of the introduction of Douglas-fir into New Zealand for use as a plantation forestry species imply that plantations were established using seed obtained from western North America, rather than planting stock, and were locally propagated thereafter (Hood and Kershaw 1975; Weston 1957). However, N. gaeumannii was most likely introduced on infected live seedlings through the forestry or ornamental nursery trade because $N$. gaeumannii can only be vectored on live or recently abscised foliage. It is highly unlikely that $N$. gaeumannii migrated to New Zealand naturally via passive ascospore dispersal, given that major dispersal barriers and vast distances exist between New Zealand and the nearest known N. gaeumannii populations in Europe and North America. The SNC fungus was present in Europe long before it was detected in New

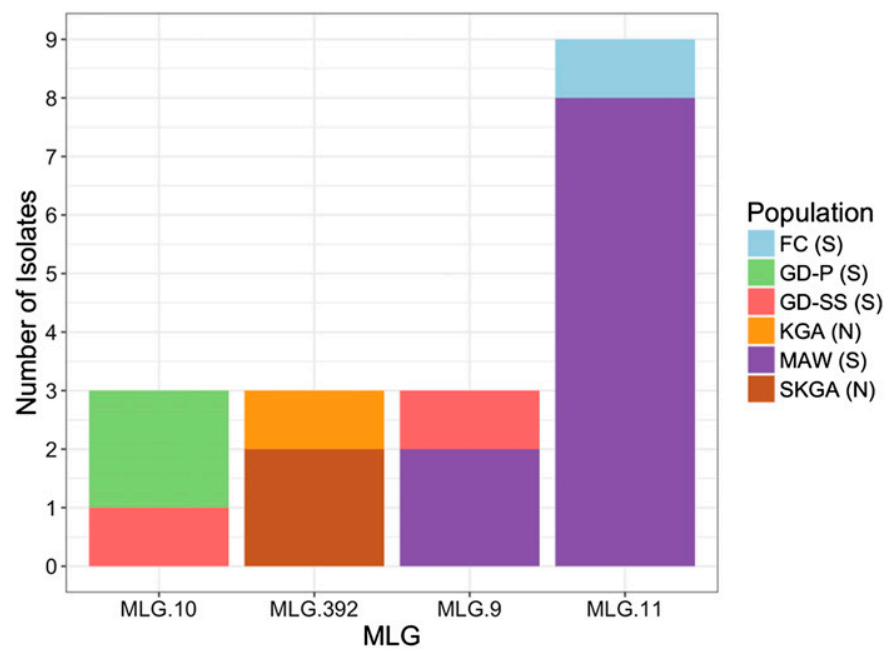

Fig. 5. Bar plot showing the abundances of four Nothophaeocryptopus gaeumannii Lineage 2 simple sequence repeat multilocus genotypes (MLGs) at six sites in the North $(\mathrm{N})$ and South $(\mathrm{S})$ Islands of New Zealand. Each bar represents a unique Lineage 2 MLG, with the colored portions of the bars corresponding to the number of isolates with that MLG at each of the sites listed in the legend: Forest Creek (FC), Golden Downs (Progeny) (GD-P), Golden Downs (Seed Source) (GD-SS), Kaingaroa (KGA), Mawhera (MAW), and South Kaingaroa (SKGA); $(\mathrm{S})=$ South Island and $(\mathrm{N})=$ North Island. 
Zealand, but Lineage 2 has only been found in coastal northwestern North America and New Zealand, which strongly suggests North America as the source.

\section{ACKNOWLEDGMENTS}

We thank J. Britt, J. F. Gardner, R. J. Hood, and W. Sutton for field and laboratory assistance; Z. Kamvar and J. Tabima for assistance in the implementation and interpretation of analyses performed with the $\mathrm{R}$ packages poppr and adegenet; J. Chang, N. Grünwald, and two anonymous reviewers whose comments helped improve this manuscript; and the many forest landowners in New Zealand who generously provided access to their lands.

\section{LITERATURE CITED}

Agapow, P., and Burt, A. 2001. Indices of multilocus linkage disequilibrium. Mol. Ecol. Notes 1:101-102.

Baquero, O. S. 2017. ggsn: North symbols and scale bars for maps created with 'ggplot2' or 'ggmap'. R package version 0.4.0. https://cran.r-project. $\mathrm{org} / \mathrm{web} /$ packages/ggsn/index.html

Bennett, P., and Stone, J. 2016. Assessments of population structure, diversity, and phylogeography of the Swiss needle cast fungus (Phaeocryptopus gaeumannii) in the U.S. Pacific Northwest. Forests 7:14.

Boyce, J. S. 1940. A needle-cast of Douglas fir associated with Adelopus gaumanni. Phytopathology 30:649-659.

Brown, J. K. M., and Hovmøller, M. S. 2002. Aerial dispersal of pathogens on the global and continental scales and its impact on plant disease. Science 297:537-541.

Castaño, C., Colinas, C., Gómez, M., and Oliva, J. 2014. Outbreak of Swiss needle cast caused by the fungus Phaeocryptopus gaeumannii on Douglasfir in Spain. New Dis. Rep. 29:19.

Dray, S., and Dufour, A.-B. 2007. The ade4 package: Implementing the duality diagram for ecologists. J. Stat. Softw. 22:1-20.

Excoffier, L., Smouse, P. E., and Quattro, J. M. 1992. Analysis of molecular variance inferred from metric distances among DNA haplotypes: Application to human mitochondrial DNA restriction data. Genet. Soc. Am. 131: 479-491.

Grünwald, N. J., Goodwin, S. B., Milgroom, M. G., and Fry, W. E. 2003. Analysis of genotypic diversity data for populations of microorganisms. Phytopathology 93:738-746.

Hansen, E. M., Stone, J. K., Capitano, B. R., Rosso, P., Sutton, W., Winton, L., Kanaskie, A., and McWilliams, M. G. 2000. Incidence and impact of Swiss needle cast in forest plantations of Douglas-fir in coastal Oregon. Plant Dis. 84:773-778.

Hartl, D. L., and Clark, A. G. 2007. Principles of Population Genetics, 4th ed. Sinauer Associates, Sunderland, MA.

Hood, I. A., and Kershaw, D. J. 1973. Distribution and life history of Phaeocryptopus gaeumannii on Douglas Fir in New Zealand (Forest Pathology Report No. 37 (unpublished)). New Zealand Forest Service, Forest Research Institute.

Hood, I. A., and Kershaw, D. J. 1975. Distribution and infection period of Phaeocryptopus gaeumannii in New Zealand. N. Z. J. For. Sci. 5: 201-208.

Hood, I. A. 1982. Phaeocryptopus gaeumannii on Pseudotsuga menziesii in Southern British Columbia. N.Z. J. For. Sci. 12:415-424.

Hood, I. A., Sandberg, C. J., Barr, C. W., Holloway, W. A., and Bradbury, P. M. 1990. Changes in needle retention associated with the spread and establishment of Phaeocryptopus gaeumannii in planted Douglas fir. Eur. J. For. Pathol. 20:418-429.

Jombart, T. 2008. adegenet: An R package for the multivariate analysis of genetic markers. Bioinformatics 24:1403-1405.

Jombart, T., and Collins, C. 2015. A tutorial for discriminant analysis of principal components (DAPC) using adegenet 2.0.0. Imperial College London, MRC Centre for Outbreak Analysis and Modelling, London.

Jombart, T., Devillard, S., and Balloux, F. 2010. Discriminant analysis of principal components: A new method for the analysis of genetically structured populations. BMC Genet. 11:94.

Kamvar, Z. N., and Grünwald, N. 2016. grunwaldlab/Population Genetics_in_R: First release [Dataset]. Online publication. Zenodo. doi: 10.5281/zenodo. 160588

Kamvar, Z. N., Brooks, J. C., and Grünwald, N. J. 2015a. Novel R tools for analysis of genome-wide population genetic data with emphasis on clonality. Front. Genet. 6:208.

Kamvar, Z. N., Larsen, M. M., Kanaskie, A. M., Hansen, E. M., and Grünwald, N. J. 2015b. Spatial and temporal analysis of populations of the sudden oak death pathogen in Oregon forests. Phytopathology 105:982-989.
Kamvar, Z. N., Tabima, J. F., and Grünwald, N. J. 2014. Poppr: An R package for genetic analysis of populations with clonal, partially clonal, and/or sexual reproduction. PeerJ 2:e281.

Liese, J. 1939. The occurrence in the British Isles of the Adelopus disease of Douglas fir. Q. J. For. 33:247-252.

Linde, C. C., Zhan, J., and McDonald, B. A. 2002. Population structure of Mycosphaerella graminicola: From lesions to continents. Phytopathology 92:946-955.

Mantel, N. 1967. The detection of disease clustering and a generalized regression approach. Cancer Res. 27:209-220.

Manter, D. K., Bond, B. J., Kavanagh, K. L., Rosso, P. H., and Filip, G. M. 2000. Pseudothecia of Swiss needle cast fungus, Phaeocryptopus gaeumannii, physically block stomata of Douglas fir, reducing $\mathrm{CO}_{2}$ assimilation. New Phytol. 148:481-491.

Marks, G. C. 1975. Swiss needle cast of Douglas fir. Australas. Plant Pathol. 4:24.

McCormick, F. A. 1939. Phaeocryptopus gaeumannii on Douglas fir in Connecticut. Plant Dis. Rep. 23:368-369.

Meinecke, E. P. 1939. The Adelopus needle cast of Douglas fir on the Pacific Coast. Department of Natural Resources, Division of Forestry, Sacramento, CA.

Ministry for Primary Industries. 2016. National Exotic Forest Description. Ministry for Primary Industries, New Zealand.

Morton, H. L., and Patton, R. F. 1970. Swiss needle cast of Douglas-fir in the Lake States. Plant Dis. Rep. 54:612-616.

Nei, M. 1972. Genetic distance between populations. Am. Nat. 106: 283-292.

Nei, M. 1978. Estimation of average heterozygosity and genetic distance from a small number of individuals. Genetics 89:583-590.

Oksanen, J., Guillaume, B., Friendly, M., Kindt, R., Legendre, P., McGlinn, D., Minchin, P. R., O'Hara, R. B., Simpson, G. L., Solymos, P., Stevens, M. H. H., Szoecs, E., and Wagner, H. 2017. vegan: Community Ecology Package. R package version 2.4-5. https://cran.r-project.org/web/packages/ vegan/index.html

Osorio, M. 2007. Detección del hongo defoliador Phaeocryptopus gaeumannii en plantaciones de Pseudotsuga menziesii de Valdivia, Chile. Bosque (Valdivia) 28:69-74.

Peace, T. R. 1962. Pathology of Trees and Shrubs with Special Reference to Britain. Clarendon Press, Oxford.

Peakall, R., and Smouse, P. E. 2006. GenAlEx 6: genetic analysis in Excel. Population genetic software for teaching and research. Mol. Ecol. Notes 6: 288-295.

Peakall, R., and Smouse, P. E. 2012. GenAlEx 6.5: Genetic analysis in Excel. Population genetic software for teaching and research-an update. Bioinformatics 28:2537-2539.

R Core Team. 2017. R: A language and environment for statistical computing. R Foundation for Statistical Computing, Vienna, Austria. https://www.Rproject.org

Ritóková, G., Shaw, D., Filip, G., Kanaskie, A., Browning, J., and Norlander, D. 2016. Swiss needle cast in western Oregon Douglas-fir plantations: 20year monitoring results. Forests 7:155.

Rivas, G. G., Zapater, M. F., Abadie, C., and Carlier, J. 2004. Founder effects and stochastic dispersal at the continental scale of the fungal pathogen of bananas Mycosphaerella fijiensis. Mol. Ecol. 13:471-482.

Rogers, J. S. 1972. Measures of genetic similarity and genetic distances. Studies in Genetics, Univ. Texas Publ. 7213:145-153.

Rohde, T. 1936. Adelopus gaeumannii n. sp. und die von ihm hervorgerufene "Schweizer" Douglasienschütte. Forstliche Wochenschr. Silva 24: 420-422.

Shannon, C. E. 2001. A mathematical theory of communication. ACM Sigmobile Mob. Comput. Commun. Rev. 5:3-55.

Slowikowski, K. 2017. ggrepel: Repulsive text and label geoms for 'ggplot2'. $\mathrm{R}$ package version 0.7.0. https://cran.r-project.org/web/packages/ggrepel/ index.html

Smith, J. M., Smith, N. H., O'Rourke, M., and Spratt, B. G. 1993. How clonal are bacteria? Proc. Natl. Acad. Sci. 90:4384-4388.

Stone, J. K., Capitano, B. R., and Kerrigan, J. L. 2008a. The histopathology of Phaeocryptopus gaeumannii on Douglas-fir needles. Mycologia 100: 431-444.

Stone, J. K., Coop, L. B., and Manter, D. K. 2008b. Predicting effects of climate change on Swiss needle cast disease severity in Pacific Northwest forests. Can. J. Plant Pathol. 30:169-176.

Stone, J. K., Hood, I. A., Watt, M. S., and Kerrigan, J. L. 2007. Distribution of Swiss needle cast in New Zealand in relation to winter temperature. Australas. Plant Pathol. 36:445.

Taylor, J. W., Jacobson, D. J., and Fisher, M. C. 1999. The evolution of asexual fungi: Reproduction, speciation and classification. Annu. Rev. Phytopathol. 37:197-246.

Temel, F., Stone, J. K., and Johnson, G. R. 2003. First report of Swiss needle cast caused by Phaeocryptopus gaeumannii on Douglas-fir in Turkey. Plant Dis. 87:1536. 
Watt, M. S., Stone, J. K., Hood, I. A., and Palmer, D. J. 2010. Predicting the severity of Swiss needle cast on Douglas-fir under current and future climate in New Zealand. For. Ecol. Manage. 260:2232-2240.

Weston, G. C. 1957. Exotic forest trees in New Zealand. Statement prepared for the 7th British Commonwealth Forestry Conference, Australia and New Zealand No. 13. New Zealand Forest Service, Wellington, New Zealand.

Wickham, H. 2016. ggplot2: Elegant graphics for data analysis. SpringerVerlag, New York. http://ggplot2.tidyverse.org/

Wilson, M., and Waldie, J. S. L. 1928. Notes on new or rare forest fungi. Trans. Br. Mycol. Soc. 13:151-156.
Winton, L. M., Hansen, E. M., and Stone, J. K. 2006. Population structure suggests reproductively isolated lineages of Phaeocryptopus gaeumannii. Mycologia 98:781-791.

Winton, L. M., Stone, J. K., and Hansen, E. M. 2007. Polymorphic microsatellite markers for the Douglas-fir pathogen Phaeocryptopus gaeumannii, causal agent of Swiss needle cast disease. Mol. Ecol. Notes 7: 1125-1128.

Yu, G., Smith, D. K., Zhu, H., Guan, Y., and Lam, T. T.-Y. 2017. ggtree: An R package for visualization and annotation of phylogenetic trees with their covariates and other associated data. Methods Ecol. Evol. 8:28-36. 